\title{
Can publicly reported data be used to understand performance in an Australian rural hospital?
}

Health Information Management Journal $1-12$

(C) The Author(s) 2020

Article reuse guidelines:

sagepub.com/journals-permissions DOI: I0.1 I77//833358320948559 journals.sagepub.com/home/himj

\author{
Sheree Lloyd, $\mathrm{PhD}, \mathrm{CHIM}{ }^{\prime} \mathbb{D}$, \\ Cynthia Cliff, $P h D^{2}(\mathbb{D}$, \\ Gerard FitzGerald, $P h D^{2}$, \\ Jean Collie, $M D^{3}$
}

\begin{abstract}
Background: Despite agreement among policymakers, funders, consumers and researchers about the value of public reporting of health information, limited attention has been paid to how it can be used to understand the performance of rural hospitals. Objective: To determine whether publicly available information can be used to measure health service performance in a rural hospital. Method: The study used performance data routinely reported for public consumption in Australia. Data across four domains, multiple measures and time periods were collected to examine access and equity; efficiency and sustainability; quality, safety and patient orientation; and employee engagement. Performance of the rural hospital was examined using a visualisation tool. Results: Visualisation of multiple measures of performance over time was achievable but required a high degree of health information management skills. Conclusion and implications: Publicly reported data can be used to represent performance for a rural hospital. Timeliness, level of detail available and peer groupings of data limits optimal utility. Consumers, clinicians and health service managers wanting to understand the performance of rural hospitals will need to use significant health information management skills to gain a picture of performance. Further research in the applied use of publicly available performance data and relevant dashboards for rural hospitals is suggested.
\end{abstract}

\section{Keywords (MeSH)}

rural health; hospitals; rural; outcome assessment; healthcare; public reporting of healthcare data; healthcare quality; access; and evaluation; health information management

Supplementary keywords

hospital performance; performance measurement

\section{Background and significance}

Countries across the globe have a growing burden of chronic disease ascribed to aging populations, and health system performance and sustainability are high on the agenda of their health leaders. Consequently, high performing hospitals and health systems are important for consumers, funders, policymakers, health service managers, politicians and for the clinicians expected to deliver an increasing volume and complexity of services (Duckett et al., 2014; Duckett and Willcox, 2015).

Public reporting of health information for transparency, accountability and for clinicians to action to improve care is well recognised (Board and Watson, 2010; Duckett et al., 2018) and reporting of performance has been shown internationally to exert a powerful effect in accelerating improvements in health services (Canaway et al., 2018a; Leeb, 2018). The Australian Institute of Health and
Welfare (AIHW) and Bureau of Health Information (BHI) New South Wales (NSW) report regularly on Australian health systems and on the health of Australians. While Australia has strong health data reporting mechanisms, a comprehensive set of indicators that can be used to determine whether the health system works in optimal ways is not yet available (Srinvasan et al., 2018).

\footnotetext{
I Griffith University, Australia

${ }^{2}$ Queensland University of Technology, Australia

${ }^{3}$ University of Wollongong, Australia

Accepted for publication July 20, 2020
}

Corresponding author:

Dr Sheree Lloyd, Senior Lecturer, Health Services Management, School of Medicine, Griffith University, Southbank Campus, Nathan, QLD 4III, Australia.

E-mail: s.lloyd@griffith.edu.au 
A review of the literature found no agreed or single definition of what constitutes "performance" or "good performance" of hospitals (Ahluwalia et al., 2017; Pronovost, 2017). Performance has been described using measures related to access, equity, cost, patient experience and the quality of care (Ahluwalia et al., 2017; Pronovost, 2017; Veillard et al., 2005; Veillard et al., 2017, 2013). Taylor et al. (2015) defined high performing hospitals as those that "consistently attained excellence across multiple measures of performance and multiple departments."

At an overall health system level, Australia performs well (Marchildon et al., 2018). International comparisons of healthcare outcomes, access to services, equity and administrative efficiency of health systems show that Australia ranks second after the United Kingdom (Schneider et al., 2017). Since 2009 in Australia, a National Health Performance Framework has reported the performance of hospitals against measures of equity, quality, safety, appropriateness and effectiveness (Australian Institute of Health and Welfare, 2020; The National Health Information and Performance Principal Committee, 2017). The intention of public reporting in Australia has been to increase accountability and transparency and to support consumers to make decisions about their health. Until recently, this topic has attracted little research (Canaway et al., 2017a, 2017b, 2018b). Public reporting is also intended for doctors, nurses, academics, health service managers and the community (Australian Institute of Health and Welfare, 2018). Hospitals and clinical professionals need to understand their own performance in comparison to peers so that they can learn from the best performers and identify areas for improvement (Duckett, 2019; Duckett et al., 2018).

Research on performance measurement in rural hospitals has received little academic scrutiny despite approximately $30 \%$ of the Australian population living in rural locations, where population health is impacted by decreased access to health services, higher rates of disease and poorer health outcomes (Australian Institute of Health and Welfare, 2014). Effective health care delivery in rural locations is influenced by difficulties in recruiting and retaining staff, fewer resources and less infrastructure. Anecdotally, there is a perception that the workload in rural health settings is high and access to resources limited, and this translates into poorer patient outcomes. This can be a further deterrent to health professionals considering work in a rural health setting. Availability of relevant performance data at a hospital level could support clinicians considering rural practice and would assist health service managers to understand performance issues, learn from and share good practice and implement improvement strategies (Duckett, 2019; Duckett et al., 2018).

\section{Current research}

The current research was part of a larger case study of a rural hospital in NSW, Australia, which used indicators reported on public websites such as My Hospitals (Australian Institute of Health and Welfare, 2017, 2018) and the NSW BHI (Bureau of Health Information, 2017, 2018b) to examine and analyse the performance of a rural hospital. The aim of the study that formed the basis of this article was to determine whether publicly available information can be used to measure health service performance in a rural hospital.

\section{Method}

\section{Sample}

The study hospital was selected for convenience; other hospital executives may have been willing to participate but were not approached. Publicly reported performance data available in 2017/2018 were collated and analysed to determine whether performance across multiple measures and timeframes could be described.

\section{Definitions}

Three definitions of performance were considered: (i) the achievement of specified targets, either clinical or administrative (Dias and Escoval, 2013); (ii) a high performing health system as one that is able to achieve its purpose (Pronovost, 2017); and (iii) high performing hospitals are those that "consistently attain excellence across multiple measure of performance, and multiple departments (Taylor et al., 2015: 1). Pronovost's (2017) and Dias and Escoval's (2013) definitions were considered too oblique, and Taylor et al's. (2015) practical and pragmatic hospital-specific definition was selected.

\section{Measures}

While data at the departmental level were not available for analysis, this study used a range of measures representing performance across different parts of the hospital. Accordingly, multiple measures of performance for the study hospital were collated, analysed and visualised for this research. Data on access and timeliness to care, costs, quality, safety, employee engagement and culture were downloaded from the AIHW MyHospitals (Australian Institute of Health and Welfare, 2017, 2018), NSW Public Service Commission (People Matters) (NSW Public Service Commission, 2017, 2018a) and the BHI websites (Bureau of Health Information, 2017). Data repositories and reports on these sites were identified through Internet searching and recognised as trusted and comprehensive sources of health information. Spreadsheets were created that included the study hospital's performance and its peers, and datasets were then analysed to establish a profile of performance and measurement descriptors. Four domains of data and multiple indicators were collected (see Figure 1). National comparisons to peers were made when data were available. For some measures (e.g. patient satisfaction) only state-based public data were available. Pragmatically, indicators were included in the analysis if, at the time of the study, data had been reported for the study site over multiple time periods and peer comparisons were available. Examples of the indicators examined are described below for each of the four domains. 


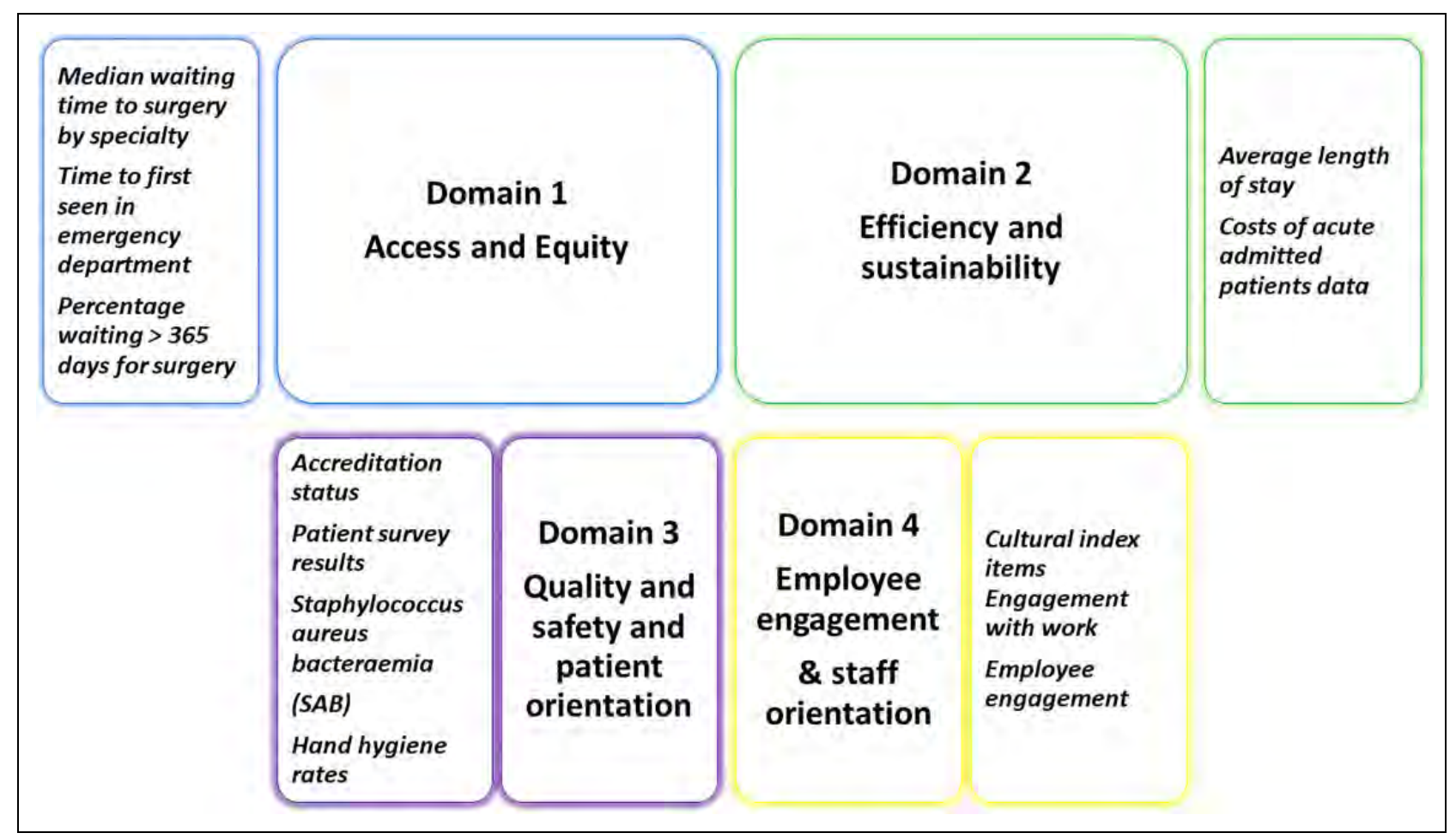

Figure I. Reported domains and indicators of performance examined in the study.

\section{Domain I: Access and equity}

- Surgery waiting times. Waiting times for surgery can have a significant impact on individuals' well-being, health and independence and waiting times by urgency are routinely reported. Measures investigated were median waiting times for surgery and percentage of patients waiting more than 365 days for surgery by specialty.

- Emergency department time to first seen and waiting times. In emergency departments, timely care, particularly for seriously ill patients, is an important measure of the performance of the hospital. The 4hour requirement for treatment and discharge from the emergency department reflects patient flow within a hospital and timely discharge to the most appropriate setting for care, be that to a ward, intensive care unit, operating theatre, discharge to patient's home or transfer to higher level of care. The National Emergency Performance Target has been used in the United Kingdom and Australia as a measure for access to timely care in emergency departments (National Health Performance Authority, 2016).

\section{Domain 2: Efficiency and sustainability}

Two publicly reported indicators for sustainability and efficiency were examined:

- Average length of stay is widely used as a proxy for efficiency as a shorter stay reduces the cost and transfers care from inpatient to less-expensive care settings (OECD, 2018).
- Cost per national weighted activity unit (NWAU) is the "average" cost of a public hospital service provided to an admitted patient.

\section{Domain 3: Quality and safety/patient orientation}

To understand quality and safety, the BHI and MyHospitals data for accreditation status, hospital-acquired infection rates, hand hygiene data and admitted patient survey rates were examined:

- Accreditation status. The value of accreditation and links to performance has been described by Braithwaite et al. (2010) and Greenfield et al. (2015). Leadership behaviours and cultural characteristics show a positive trend between accreditation and clinical performance (Braithwaite et al., 2010).

- Healthcare-associated infections. Staphylococcus aureus (S aureus) bacteraemia (SAB) is an infection that can be acquired during medical care or treatment in a hospital. Hospitals aim to have as few cases as possible as contracting a SAB bloodstream infection can be life-threatening (Australian Institute of Health and Welfare, 2018).

- Hand hygiene. Correctly performed hand hygiene can minimise the risk of healthcare-associated infections. Hospitals regularly audit and report on hand hygiene compliance to the AIHW and available on their MyHospitals website.

- Adult admitted patient survey results. Annually, in NSW, patients admitted to public hospitals are surveyed using the Admitted Patient Survey and reported on the BHI website. In 2017, patients were 


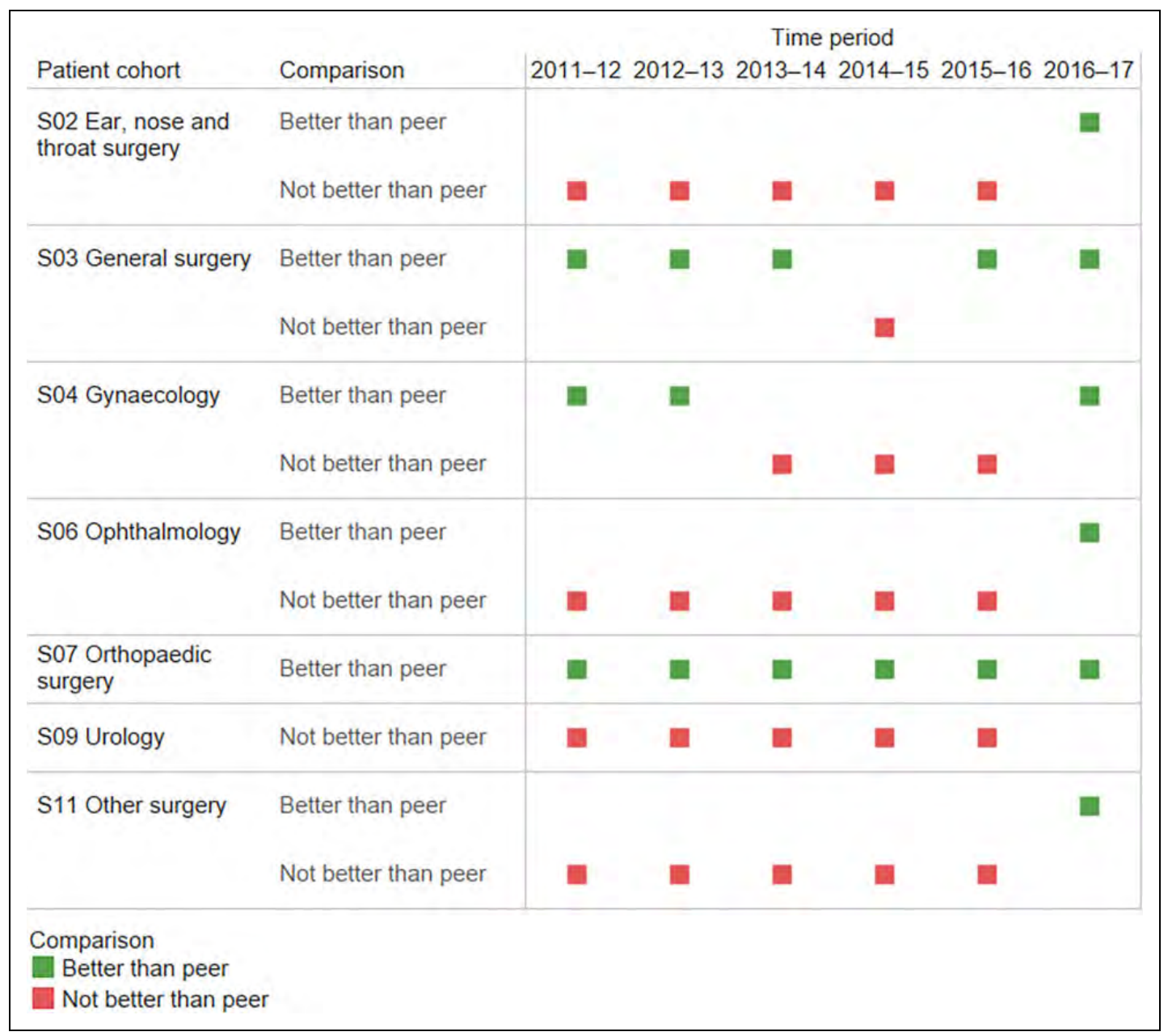

Figure 2. Median wait time to surgery at study hospital compared with peers over time.

asked 86 questions addressing their experiences and outcomes of care. Results are deemed significantly different to NSW according to a $95 \%$ confidence intervals and shown in green (positive difference) and red (negative difference) (Bureau of Health Information, 2018a). Comparisons were made of all hospitals categorised by the BHI NSW as Peer Group $\mathrm{C}$ and a comparative peer hospital. Peer Group C includes 40 hospitals across NSW.

\section{Domain 4: Employee engagement/orientation}

Each year, the NSW Government surveys staff and asks employees about experiences with their work environment, individuals' own work and working with their team, managers and their host organisation (the Local Health District (LHD)) (NSW Public Service Commission, 2019). The Employee Engagement Index from the 2017 and $2018 \mathrm{Cul}-$ ture Survey was examined (NSW Public Service Commission, 2017, 2018b). The Index is a composite measure and is weighted.

\section{Data analysis}

Data were analysed separately for each domain. Tableau software was used to analyse and present the data to show performance across time for each indicator. Data visualisation and business intelligence tools are used by healthcare organisations to portray data in meaningful ways with high visual appeal and to support intuitive interpretations (Brigham, 2016; Chorpita et al., 2008; Ertug et al., 2018; Ghazisaeidi et al., 2015). The study site hospital was considered "better than peer" if, and dependent upon the unit of measure, their performance was better than or equal to published peer results. Performance for each indicator when data were publicly available were also analysed over multiple time periods.

Ethics approval was received from the North Coast New South Wales LHD Human Research and Ethics Committee (HREC) Low and negligible risk (LNR 176/17/NCC/127), and Site-Specific Assessment (LNR SSA/17/NCC/129); and Queensland University of Technology (1800000117).

\section{Results}

Results for selected indicators are reported for each domain to demonstrate the comparative performance and to protect the privacy of the study hospital (Online Appendix 1 shows the full set of indicators examined, data sources, level and units of measure used for comparison for each domain). Visualisation of data allowed the researchers to represent 


\begin{tabular}{|c|c|c|c|c|c|c|c|}
\hline Patient cohort & Comparison & $2011-12$ & $2012-13$ & $\begin{array}{r}\text { Time } \\
2013-14\end{array}$ & $\begin{array}{l}\text { period } \\
2014-15\end{array}$ & $2015-16$ & $2016-17$ \\
\hline \multirow{2}{*}{$\begin{array}{l}\text { S02 Ear, nose and } \\
\text { throat surgery }\end{array}$} & Better than peer & & 믈 & 国 & 圆 & 目 & 圆 \\
\hline & Not better than peer & 口 & & & & & \\
\hline S03 General surgery & Better than peer & 国 & 国 & 目 & 回 & 圆 & 目 \\
\hline \multirow[t]{2}{*}{ S04 Gynaecology } & Better than peer & & 몸 & 무 & 물 & 묘 & 묘 \\
\hline & Not better than peer & 믐 & & & & & \\
\hline \multirow[t]{2}{*}{ S06 Ophthalmology } & Better than peer & & 모 & 무 & 무 & $\mathbf{E}$ & $\mathbf{a}$ \\
\hline & Not better than peer & 口 & & & & & \\
\hline $\begin{array}{l}\text { S07 Orthopaedic } \\
\text { surgery }\end{array}$ & Better than peer & 묘 & 믐 & 물 & 몸 & 묘 & 口 \\
\hline S09 Urology & Not better than peer & 밈 & $\mathbf{a}$ & 뭄 & 뭄 & $\mathbf{a}$ & \\
\hline S11 Other surgery & Not better than peer & 무 & 믐 & $\mathbf{a}$ & 므 & 目 & $\mathbf{E}$ \\
\hline $\begin{array}{l}\text { Comparison } \\
\text { Better than peer } \\
\text { Not better than pee }\end{array}$ & & & & & & & \\
\hline
\end{tabular}

Figure 3. Percentage of patients who waited more than 365 days for surgery by specialty at study hospital compared with peers over time.

the indicators in a way that made them easy to interpret using a "traffic light" system (red: performance not better than peers; green: performance better or equal to peers (Hoelscher and Mortimer, 2018; Tableau Software Inc, 2018).

\section{Domain I: Access and equity}

- Surgery waiting times. Figure 2 shows the median waiting time for surgery by specialty across multiple time periods. This demonstrates that for some specialties (orthopaedics and general surgery), equal or better than peer performance was achieved over time for median days waiting for intended surgeries. Figure 3 shows the percentage of patients waiting more than 365 days for surgery. The study hospital performed better than peers for ear, nose and throat surgery, general surgery, gynaecology, ophthalmology and orthopaedics. Other surgery did not compare well with peer performance, possibly reflecting a lack of access to the specific specialties grouped in "other surgery."

- Emergency department time to first seen and waiting times. Figure 4 shows the visualised results for the time to first seen indicator. This demonstrated that the performance for triage Category 1 patients was better or equal to peers over a sustained period; however, triage categories $2-4$ did not perform better than peers. For triage 5, the reported data did not meet the criteria needed to calculate this item in the years 2011-2015, limiting analysis of this group (Australian Institute of Health and Welfare, 2018). The National Emergency Performance Target when compared with peers as defined by MyHospitals showed performance for the study hospital did not consistently perform better over time.

\section{Domain 2: Efficiency and sustainability}

- Cost per NWAU. Figure 5 shows the study hospital compared to peer group hospitals in NSW for cost per NWAU. The chart shows that the study hospital is the most efficient of its peers in NSW but more expensive than similar peers Australia wide. At the time of the study, costing information from MyHospitals was not available after 2013-2014. Historical costing data too may be influenced by accounting, counting and other practices and as such could impact upon the reliability of these analyses. More recent costing data were available through the Independent Hospital Pricing Authority's National Benchmarking Portal; however, this was not accessed by the researcher as it was not covered by the Ethical approval and access is only granted to health organisation employees through a jurisdiction contact (Independent Hospital Pricing Authority, 2018).

- Average length of stay. Figure 6 shows that the study hospital has performed well since 2014 for two categories of patients: heart failure and knee 


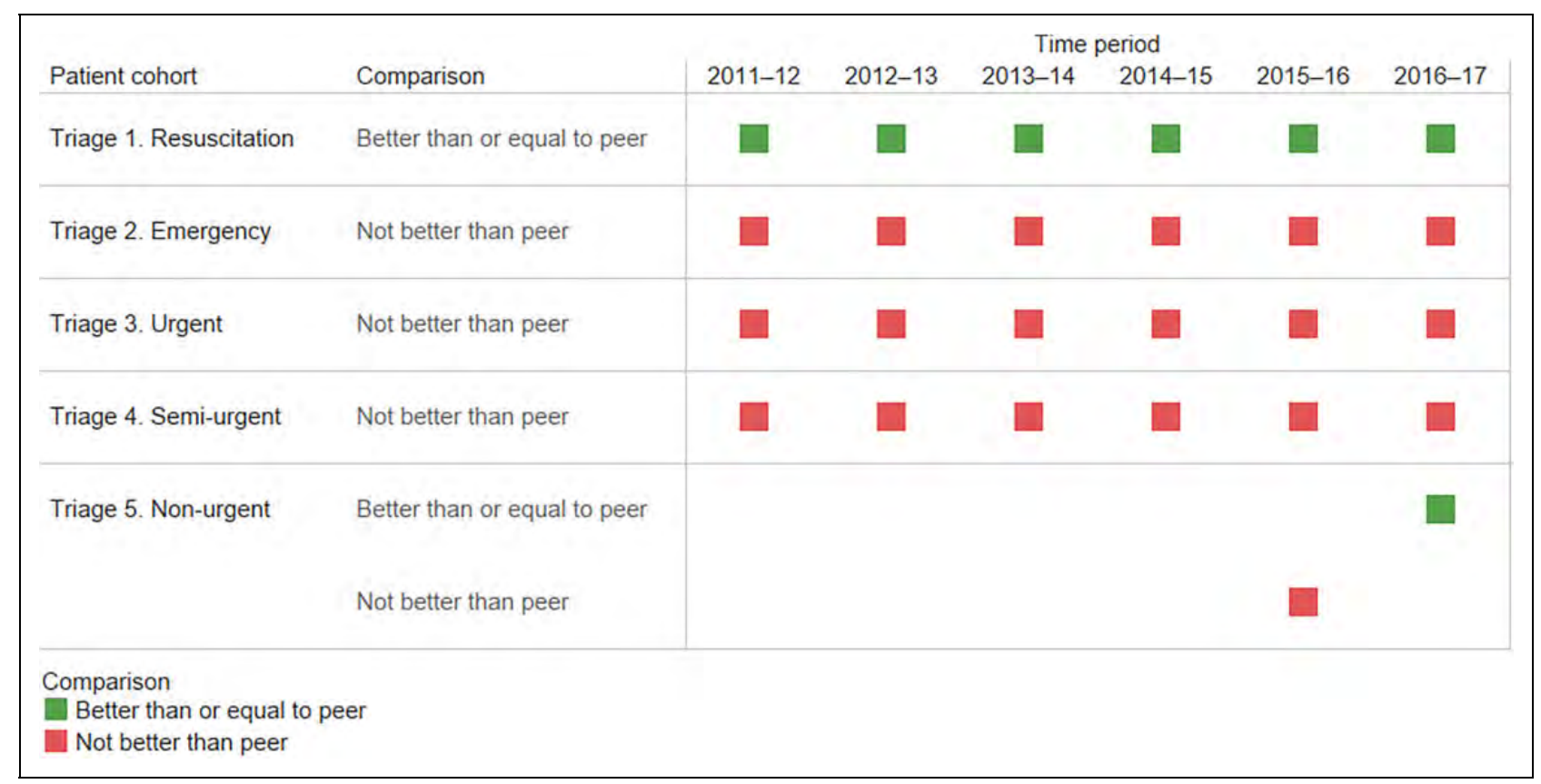

Figure 4. Emergency department data percentage of patients seen on time by triage at study hospital comparison with peers over time.

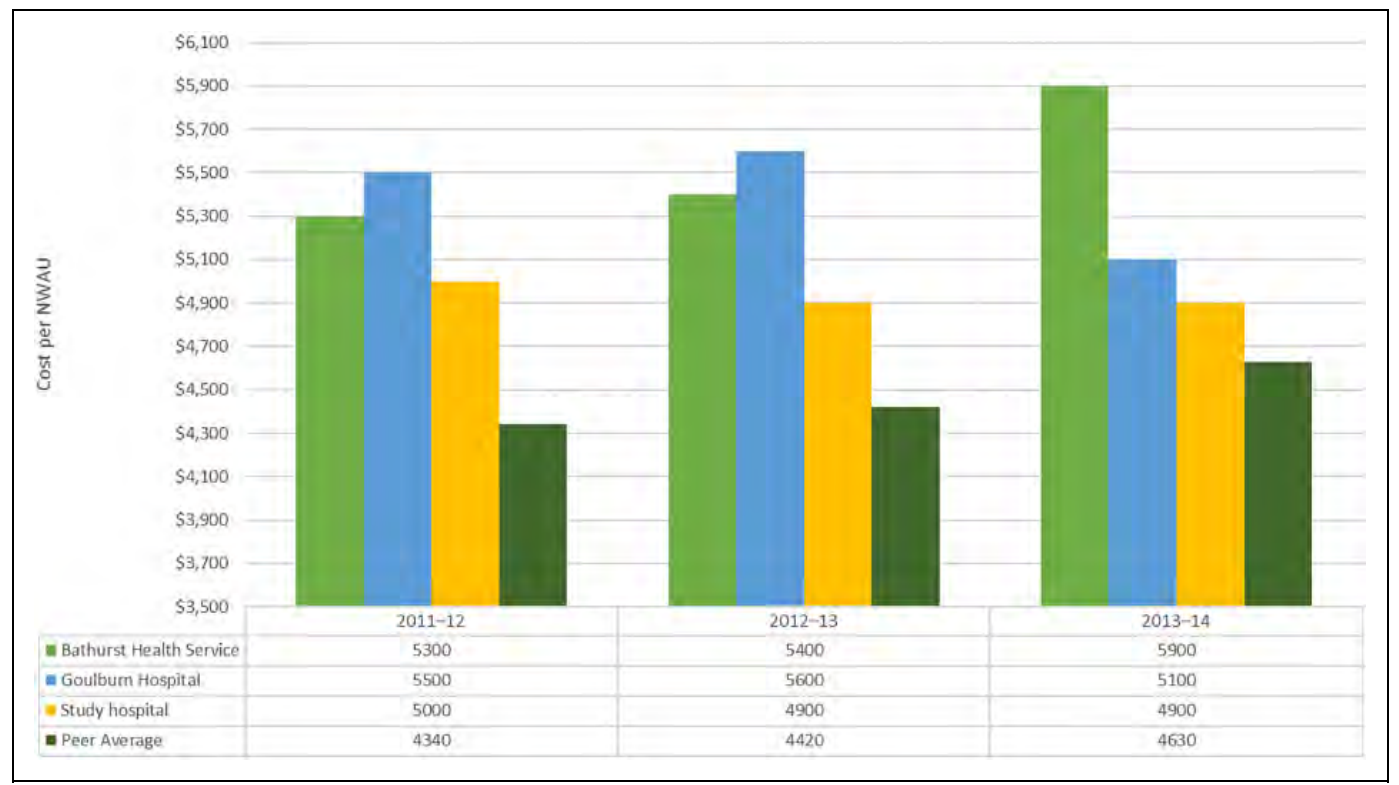

Figure 5. Comparison of NSW major regional hospitals cost per NWAU and National peers over time.

replacement and have average length of stays better or equal to peer hospitals consistently over this time. In the rural health context, alternative settings for post-acute care for chronic conditions are limited. The performance in other surgical categories may reflect local practices or the inability to refer to alternative post-acute settings.

\section{Domain 3: Quality and safety/patient orientation}

Results for quality and safety indicators and patient orientation are presented below:
- Accreditation status. The study hospital is currently accredited by the Australian Council of Healthcare Standards. Accreditation has been achieved over many years, with good results. At the time of the study, the most recent survey had been conducted in October 2016 and produced full accreditation, which was granted in January 2017.

- Healthcare-associated infections. The rate per 10,000 bed days for all bloodstream infections was compared to peer hospitals. Figure 7 shows that the study hospital performed better than the comparative 


\begin{tabular}{|c|c|c|c|c|c|c|c|}
\hline \multirow[b]{2}{*}{ Category } & \multirow[b]{2}{*}{ Comparison } & \multicolumn{6}{|c|}{ Time period } \\
\hline & & $2011-12$ & $2012-13$ & 2013-14 & 2014-15 & $2015-16$ & $2016-17$ \\
\hline Caesarean delivery & $\begin{array}{l}\text { Not better than } \\
\text { peer }\end{array}$ & 国 & 回 & 回 & 回 & 回 & 回 \\
\hline Cellulitis & $\begin{array}{l}\text { Not better than } \\
\text { peer }\end{array}$ & 回 & 回 & $\square$ & 回 & 国 & 回 \\
\hline \multirow[t]{2}{*}{$\begin{array}{l}\text { Chronic Obstructive Pulmonary Disease } \\
\text { (without complications) }\end{array}$} & $\begin{array}{l}\text { Not better than } \\
\text { peer }\end{array}$ & & & 回 & 回 & & 回 \\
\hline & Better than peer & 圄 & 回 & & & 回 & \\
\hline \multirow[t]{2}{*}{ Gallbladder removal } & $\begin{array}{l}\text { Not better than } \\
\text { peer }\end{array}$ & 目 & 回 & 回 & 回 & 回 & \\
\hline & Better than peer & & & & & & 回 \\
\hline \multirow[t]{2}{*}{ Heart failure (without complications) } & $\begin{array}{l}\text { Not better than } \\
\text { peer }\end{array}$ & & & $\square$ & & & \\
\hline & Better than peer & & & & 回 & 回 & 回 \\
\hline \multirow[t]{2}{*}{ Hip replacement } & $\begin{array}{l}\text { Not better than } \\
\text { peer }\end{array}$ & & & & 回 & 미 & \\
\hline & Better than peer & & & & & & 回 \\
\hline $\begin{array}{l}\text { Kidney and urinary tract infections (with } \\
\text { complications) }\end{array}$ & Better than peer & & & & & 回 & \\
\hline $\begin{array}{l}\text { Kidney and urinary tract infections (without } \\
\text { complications) }\end{array}$ & $\begin{array}{l}\text { Not better than } \\
\text { peer }\end{array}$ & & & 口 & 国 & 回 & 回 \\
\hline Knee replacement & Better than peer & & & & 回 & 밈 & $\square$ \\
\hline Vaginal delivery & $\begin{array}{l}\text { Not better than } \\
\text { peer }\end{array}$ & 回 & 口 & 口 & 回 & $\square$ & 回 \\
\hline $\begin{array}{l}\text { Comparison } \\
\text { Not better than peer } \\
\text { Better than peer }\end{array}$ & & & & & & & \\
\hline
\end{tabular}

Figure 6. Length of stay study hospital comparison with National peer hospitals over time.

$\begin{aligned} & \text { SAB rate per 10,000 bed } \\ & \text { days }\end{aligned}$
$\begin{aligned} & \text { Better than or equal to } \\ & \text { peer }\end{aligned}$
Not better than peer
SAB rate per 10,000 bed days
Better than or equal to peer
Not better than peer

Figure 7. Staphylococcus aureus bacteraemia infections at study hospital comparisons to National peers over time.

peer hospitals consistently over time except for the 2011-2012 and 2016-17 periods. Continued monitoring and further investigation of these indicators will identify changes in clinical practice or whether this was an aberration.

- Hand hygiene. Data from MyHospitals shows that the study hospital had consistently higher rate than the national benchmark measure for hand hygiene compliance (see Figure 8). Early time periods in the data observed more than 200 moments of hand hygiene, while the later five periods observed more than 500 and up to 2,020 moments. More recent data were not available at the individual hospital level at the time of this study.

- Adult Admitted Patient Survey results. Survey responses for Access and Timeliness and Hygiene and Safety for a close peer hospital and NSW are represented in Table 1. For each hospital, the questions where responses were significantly less favourable (shown in red) and those significantly more favourable than NSW (shown in green) were analysed.

Responses from patients in the study hospital for the question related to nurse's hand hygiene when compared to NSW showed significantly more favourable responses. Questions related to doctor's hand hygiene and checking of identification showed more favourable responses at the study hospital than the comparative peer but they were non-significant. Table 2 shows results from the Admitted Patient Survey for the study hospital, NSW and a peer rural hospital for access and timeliness. The study hospital 


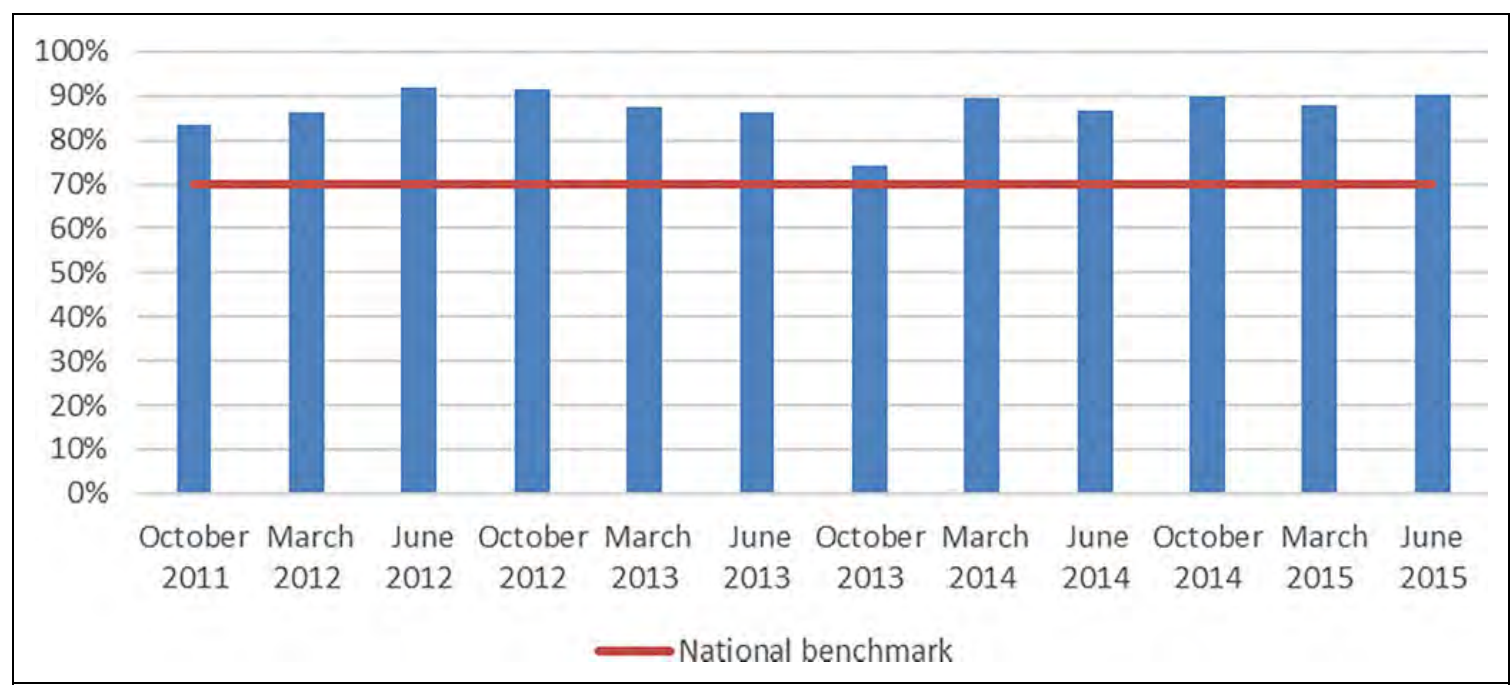

Figure 8. Hand hygiene compliance rates for study hospital compared with National benchmark by quarter over time.

Table I. Results from the NSW admitted patient survey 2017 for the study hospital for questions related to safety and quality with comparisons to NSW and rural peer. ${ }^{\text {a }}$

\begin{tabular}{|c|c|c|c|c|c|c|}
\hline Question text & Response & NSW & Minimum & Maximum & $\begin{array}{l}\text { Study } \\
\text { hospital }\end{array}$ & $\begin{array}{l}\text { Comparison } \\
\text { rural peer }\end{array}$ \\
\hline $\begin{array}{l}\text { Did you see nurses wash their hands, or use hand gel to clean } \\
\text { their hands, before touching you? }\end{array}$ & Yes, always & 61 & 49 & 80 & 70 & 62 \\
\hline $\begin{array}{l}\text { Did you see doctors wash their hands, or use hand gel to clean } \\
\text { their hands, before touching you? }\end{array}$ & Yes, always & 53 & 42 & 65 & 54 & 50 \\
\hline $\begin{array}{l}\text { Did nurses ask your name or check your identification band } \\
\text { before giving you any medications, treatments or tests? }\end{array}$ & Yes, always & 91 & 83 & 98 & 95 & 89 \\
\hline
\end{tabular}

${ }^{a}$ Boxes shaded in green showed significantly more favourable results than NSW figures (Bureau of Health Information, 2017).

Source: Admitted Patient Survey NSW (Bureau of Health Information, 2017).

Table 2. Results from the NSW admitted patient survey 2017 for the study hospital, NSW and a peer rural hospital for access and timeliness. $^{\text {a }}$

\begin{tabular}{|c|c|c|c|c|c|c|}
\hline Question text & Response & NSW & Minimum & Maximum & $\begin{array}{l}\text { Study } \\
\text { hospital }\end{array}$ & $\begin{array}{l}\text { Comparison } \\
\text { rural peer }\end{array}$ \\
\hline $\begin{array}{l}\text { Do you think the amount of time you spent in the emergency } \\
\text { department was...? }\end{array}$ & About right & 67 & 38 & 93 & 85 & 78 \\
\hline On the day you left hospital, was your discharge delayed? & No & 79 & 7I & 98 & 94 & 73 \\
\hline
\end{tabular}

${ }^{a}$ Boxes shaded in green showed significantly more favourable results than NSW figures (Bureau of Health Information, 2017). Source: Admitted Patient Survey NSW (Bureau of Health Information, 2017).

showed significantly more favourable responses for questions related to timeliness of care in the emergency department and delays to discharge.

\section{Domain 4: Employee engagement/orientation}

Table 3 shows excerpts from the Employee Engagement Index from the 2017 and 2018 Culture Survey. Significant differences are highlighted in red (requiring attention) and green (best practice) (NSW Public Service Commission, 2018a). The table shows the scores for employee engagement and engagement with work for the study hospital compared to other sites in the LHD. This showed that while $67 \%$ of employees were engaged with their work in 2018 , the measure reflected that employee engagement required attention.

\section{All domains}

Data from all domains and indicators were tabulated to provide an overall picture of the performance of the study hospital. Visualisation of the four domains and the performance of the study hospital is shown in Figure 9. The study hospital demonstrated evidence of strong performance for several domains analysed, including access to identified surgical procedures, timely access to care for those with life-threatening conditions in the emergency department, cost per weighted separation, hand hygiene, hospital 
Table 3. Study hospital "People Matter Culture Index" 2017 and 2018 results for employee engagement compared to NSW LHD and health cluster. ${ }^{a}$

\begin{tabular}{|c|c|c|c|c|c|c|}
\hline \multirow{2}{*}{$\frac{\text { Question groupings }}{\text { Composite measure }}$} & \multicolumn{3}{|c|}{2017} & \multicolumn{3}{|c|}{2018} \\
\hline & NSW Health & LHD & Study hospital & NSW Health & LHD & Study hospital \\
\hline Employee engagement & 64 & 57 & 54 & 65 & 59 & 53 \\
\hline Engagement with work & 45 & 67 & 59 & 73 & 70 & 67 \\
\hline
\end{tabular}

${ }^{a}$ Boxes shaded in red showed less favourable results than LHD and NSW figures.

Source: NSW Public Service Commission (2017, 2018a).

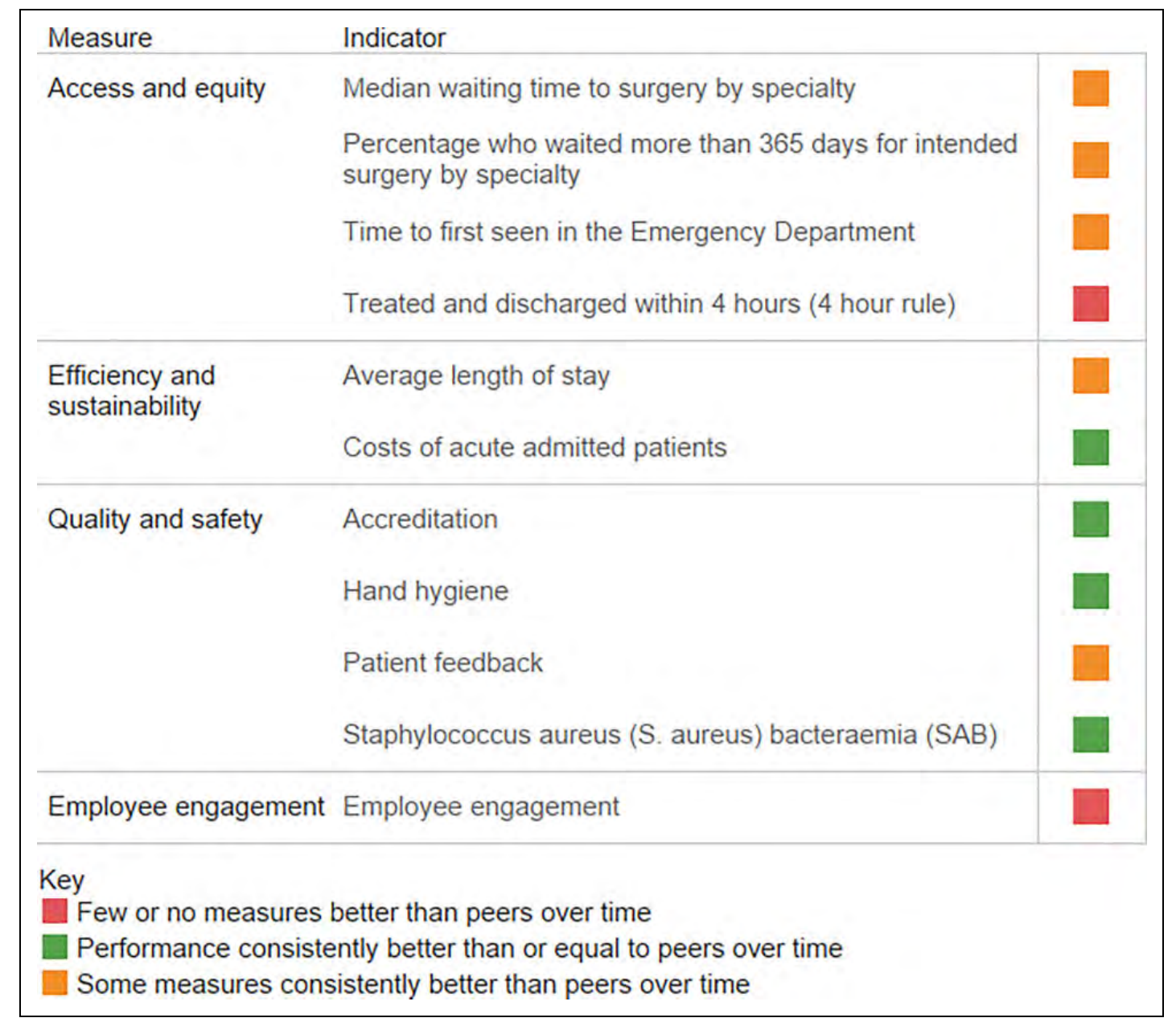

Figure 9. Study hospital performance, multiple indicators for publicly reported indicators compared with peers.

associated infections and patient feedback on the experience and outcomes of care.

\section{Discussion}

Findings of this study have added to our understanding of the utility of publicly reported performance data. The study has demonstrated that these data can be used to describe the performance of a rural hospital using multiple measures over time. The MyHospitals website makes the data accessible and downloadable in spreadsheet formats and includes hospital data and peer benchmarks. The BHI in NSW, since the study was completed, now applies visualisation tools to enable comparison and interpretation of results at the hospital level and with peer comparisons (Bureau of Health Information, 2018b). We found that while publicly available data were relatively current, there are constraints in using historical data to inform quality improvement activities and for addressing performance issues in real time. Further, reporting bodies focus at the macro level and data are not available at clinical department or clinician level. Data reporting costs, process outcomes and patient experiences are publicly available but aggregated at different levels and peer groupings. Gaps exist as not all jurisdictions collect and report all items.

Utilising visualisation tools, a representation of performance across multiple measures and time was able to be obtained but required a significant amount of health 
information management expertise. For small rural hospitals, gaining a depiction of performance utilising an agreed set of measures, collected (ideally) in real time, could aid them to understand their performance better. This could support the early identification of potential quality issues and lead to timely intervention or quality improvement initiatives. This is supported by Canaway and colleagues, who conducted a number of different studies on the topic of public reporting of performance data in health $(2017 \mathrm{a}$, $2017 b, 2018 a, 2018 b$ ). They noted that agreement on relevancy of indicators, data granularity, time delays between collection and reporting and the ability to report for small jurisdictions are all necessary for the effective implementation of public reporting of hospital performance data in Australia (Canaway et al., 2017a).

Of note, the peer groupings assigned by the BHI and MyHospitals are organised for different levels of granularity and bundling depending upon the items reported. MyHospitals data collection, from where most data for this study were sourced, allocated the study hospital into a peer group called "medium regional hospital with an emergency department." This group includes an array of hospitals with various resourcing and staffing differences. The impact of this is that "like with like" comparisons across all domains is difficult and consequently limits comparability. Costing and length of stay data can also be impacted by variation in counting and accounting practices across jurisdictions.

It is also relevant to note that since the study was completed, bodies such as the BHI NSW, Healthcare Observer are reporting a dashboard of measures, including patient feedback, and continue to enhance and strengthen approaches to public reporting. MyHospitals now present single measures over time with comparisons to peers but not multiple measures over time (Australian Institute of Health and Welfare, 2019). Ongoing enhancements to these sites and reporting performance across time and multiple measures could enable the identification of high performing hospitals and to learn from those performing well and to identify where quality improvement and other initiatives may be required.

\section{Conclusion}

We tested the availability and viability of measuring performance across multiple measures over time for a rural hospital and have demonstrated that this is possible. Routinely reported data can be used however there is no "onestop-shop" where a dashboard of performance across multiple measures over time can be accessed. We believe that the usefulness of publicly reported data collections is impacted by a number of factors. These are the timeliness of data, how peer groups are reported at different levels of granularity depending on the item reported, and the level of health information management skills required to consolidate and visualise.

We demonstrated that a representation of high performance, "excellence across multiple measures of performance and multiple departments" can be achieved
(Taylor et al., 2015). However, the data need to be sourced, combined and presented using visualisation tools so that they can be interpreted and used by health service managers and clinicians. Managers and clinicians do not have the time or skills in most instances to do this. The appropriate allocation of funding to develop comprehensive performance dashboards that enable hospital comparisons could enable managers and clinicians to identify and then learn from the "best" leading to improvements in performance (Duckett, 2019).

Importantly, effective use of data is to understand their role as indicative rather than definitive and that they should be used in combination with qualitative and descriptive information from the local context (Mannion and Braithwaite, 2012; Mannion and Smith, 2018). Data are essential for the ongoing evaluation of policy intervention and innovation adoption in health. Without publicly reported data, we cannot expect hospitals, managers and clinicians to clean up their data, review practice and be held accountable.

The development of a hospital dashboard that could be applied to rural and other hospital settings might include those suggested by Veillard et al. (2005, 2013, 2017). They described a set of measures covering sustainability (optimal use of available resources) and equity, clinical effectiveness (outcomes and appropriateness of care), patient centredness and integration (care continuity, timely care that meets patient expectations), safety (care processes that prevent or reduce harm and uptake of evidence), responsive governance (to the needs of the community, health promoting and innovative) and staff orientation (highly qualified staff, positive and enabling work environment) (Veillard et al., 2005, 2013, 2017). These domains and indicators are consistent with those applied to measure system wide performance covered by Australia's Health Performance Framework (The National Health Information and Performance Principal Committee, 2017). We would though strongly recommend the inclusion of patient reported outcome measures to inform care delivery processes and patient centred care (Australian Institute of Health and Welfare, 2020; Basch, 2017; Commonwealth of Australia, 2017).

Usability and interpretations of the data are limited as peer groupings for hospitals differ depending on the collection. Providing the option for clinicians and hospitals to select a relevant peer for comparison when accessing publicly reported data would be one way to remedy this.

Further understanding of performance, how it can be measured in meaningful ways and data presented to the public to gain a comprehensive overview of hospital performance is essential. A dashboard for rural and other hospital performance could be the focus of further research and development. This might involve determining specific indicators, meaningful to practice in the rural context. Further research to determine valid measures of the outcomes of care, patient experiences and collection of these items consistently across states and territories for public reporting is also suggested. 


\section{Authors' note}

This research was part of a larger project completed for a $\mathrm{PhD}$ of the first author.

\section{Declaration of conflicting interests}

The authors declared no potential conflicts of interest with respect to the research, authorship, and/or publication of this article.

\section{Funding}

The authors received no financial support for the research, authorship, and/or publication of this article.

\section{ORCID iDs}

Sheree Lloyd, PhD, CHIM (D) https://orcid.org/0000-0001-51354771

Cynthia Cliff, PhD D https://orcid.org/0000-0002-8226-491X

\section{Supplemental material}

Supplemental material for this article is available online.

\section{References}

Ahluwalia SC, Damberg CL, Silverman M, et al. (2017) What defines a high-performing health care delivery system: a systematic review. Joint Commission Journal on Quality and Patient Safety 43(9): 450-459. Elsevier Inc.

Australian Institute of Health and Welfare (2014) Australia's Health 2014: In Brief. Cat. no. AUS 181. Canberra: AIHW.

Australian Institute of Health and Welfare (2017) MyHospitals. Available at: http://www.myhospitals.gov.au/ (accessed 21 January 2017).

Australian Institute of Health and Welfare (2018) MyHospitals. Available at: https://www.myhospitals.gov.au/hospital/ $1155 \mathrm{H} 2100 /$ grafton-base-hospital/healthcare-associated-infec tions (accessed 6 November 2017).

Australian Institute of Health and Welfare (2019) MyHospitals. Available at: https://www.myhospitals.gov.au/compare-hospi tals (accessed 8 November 2019).

Australian Institute of Health and Welfare (2020) National Health Performance Framework. Available at: https://www.aihw.gov. au/reports-data/indicators/australias-health-performanceframework (accessed 2 April 2020).

Basch E (2017) Patient-reported outcomes - harnessing patients' voices to improve clinical care. New England Journal of Medicine 376(2): 103-105.

Board N and Watson D (2010) Using what we gather - harnessing information for improved care. Medical Journal of Australia 193(8): 93-94.

Braithwaite J, Greenfield D, Westbrook J, et al. (2010) Health service accreditation as a predictor of clinical and organisational performance: a blinded, random, stratified study. Quality \& Safety in Health Care 19: 14-21.

Brigham TJ (2016) Feast for the eyes: an introduction to data visualization. Medical Reference Services Quarterly 35(2): 215-223. Taylor \& Francis.

Bureau of Health Information (2017) Admitted Adult Patient Survey 2017 Results. Available at: http://www.bhi.nsw.gov.au/ BHI_reports/snapshot_reports/adult-admitted-patient-survey2017 (accessed 3 December 2019).
Bureau of Health Information (2018a) Measurement Matters: Development of patient experience key performance indicators for local health districts in NSW.

Bureau of Health Information (2018b) Healthcare Observer. Available at: http://www.bhi.nsw.gov.au/Healthcare_Obser ver (accessed 1 October 2018).

Canaway R, Bismark M, Dunt D, et al. (2017a) Perceived barriers to effective implementation of public reporting of hospital performance data in Australia: a qualitative study. $B M C$ Health Services Research 17(1): 391.

Canaway R, Bismark M, Dunt D, et al. (2017b) Public reporting of clinician-level data. Medical Journal of Australia 207(6): 231-232.e1.

Canaway R, Bismark M, Dunt D, et al. (2018a) Public reporting of hospital performance data: views of senior medical directors in Victoria, Australia. Australian Health Review 42(5): 591-599.

Canaway R, Bismark M, Dunt D, et al. (2018b) "What is meant by public?": stakeholder views on strengthening impacts of public reporting of hospital performance data. Social Science and Medicine 202: 143-150. Elsevier.

Chorpita BF, Bernstein A and Daleiden EL (2008) Driving with roadmaps and dashboards: using information resources to structure the decision models in service organizations. Administration and Policy in Mental Health and Mental Health Services Research 35(1-2): 114-123.

Commonwealth of Australia (2017) Shifting the Dial: 5 Year Productivity Review. Report No. 84.

Dias C and Escoval A (2013) Improvement of hospital performance through innovation: toward the value of hospital care. The health care manager 32(2): 129-140.

Duckett S (2019) You can review an airline, so why not a hospital? It's time for health sector scorecards - Opinion. Australian Broadcasting Commission 21 November. Available at: https:// www.abc.net.au/news/2019-11-21/time-for-doctor-and-hospi tal-scorecards-australia/11693000 (accessed 23 November 2019).

Duckett S and Willcox S (2015) The Australian Health Care System. The Australian Healthcare System. 5th ed. Melbourne: Oxford University Press.

Duckett S, Breadon P, Jorm C, et al. (2014) Controlling Costly Care: A Billion-dollar Hospital Opportunity. Melbourne: Report for Grattan Institute.

Duckett SJ, Jorm C, Danks L, et al. (2018) All Complications Should Count: Using Our Data to Make Hospitals Safer. Carlton: Grattan Institute. DOI: 10.1088/1742-6596/1025/1/ 012046.

Ertug G, Gruber M, Nyberg A, et al. (2018) From the Editors - a brief primer on data visualization opportunities in management research. Academy of Management Journal 61(5): 1613-1625.

Ghazisaeidi M, Safdari R, Torabi M, et al. (2015) Development of performance dashboards in healthcare sector: key practical issues. Acta Informatica Medica 23(5): 317-321.

Greenfield D, Hinchcliff R, Banks M, et al. (2015) Analysing 'big picture' policy reform mechanisms: the Australian health service safety and quality accreditation scheme. Health Expectations 18(6): 3110-3122.

Hoelscher J and Mortimer A (2018) Using Tableau to visualize data and drive decision-making. Journal of Accounting Education 44: 49-59. Elsevier. 
Independent Hospital Pricing Authority (2018) National benchmarking portal: user FactSheet. Available at: https://www. ihpa.gov.au/what-we-do/data-collection/national-benchmark ing-portal (3 December 2019).

Leeb K (2018) Does health system performance reporting stimulate change? Healthcare Management Forum 31(6): 235-238.

Mannion R and Braithwaite J (2012) Unintended consequences of performance measurement in healthcare: 20 salutary lessons from the English National Health Service. Internal Medicine Journal 42(5): 569-574.

Mannion R and Smith J (2018) Hospital culture and clinical performance: Where next? BMJ Quality \& Safety 27: 179-181.

Marchildon GP, Ludlow K, Boyling C, et al. (2018) The comparative performance of the Canadian and Australian health systems. Healthcare Management Forum 31(6): 239-244.

National Health Performance Authority (2016) MyHospitals. Available at: http://www.myhospitals.gov.au/about-myhospi tals (accessed 31 March 2016).

NSW Public Service Commission (2017) Northern NSW Local Health District People Matter 2017. Sydney: NSW Government.

NSW Public Service Commission (2018a) Northern NSW Local Health District People Matters Survey. Available at: https:// nnswlhd.health.nsw.gov.au/about/northern-nsw-local-healthdistrict/ (accessed 26 November 2018).

NSW Public Service Commission (2018b) People Matters Survey. Available at: https://www.psc.nsw.gov.au/reports-data/ people-matter-employee-survey (accessed 3 December 2019).

NSW Public Service Commission (2019) People Matters Survey. Available at: https://www.psc.nsw.gov.au/reports—data/peo ple-matter-employee-survey (accessed 3 December 2019).

OECD (2018) OECD Data Length of Hospital Stay. Available at: https://data.oecd.org/healthcare/length-of-hospital-stay.htm (accessed 1 November 2018).

Pronovost PJ (2017) High-performing health care delivery systems: High performance toward what purpose? Joint
Commission Journal on Quality and Patient Safety 43(9): 448-449. Elsevier Inc.

Schneider EC, Sarnak DO, Squires D, et al. (2017) Mirror, Mirror 2017: International Comparisons Reflect Flaws in US Health Care. Available at: commonwealthfund.org.

Srinvasan U, Ramachandran D, Quilty C, et al. (2018) Flying blind: Australian researchers and digital health. Volume 2: Health Data Series, Digital Health Cooperative Research Centre, Sydney. DOI: 10.1016/S0262-4079(14)62108-4.

Tableau Software Inc (2018) What is Tableau? Available at: https://www.quora.com/What-is-Tableau (4 December 2019).

Taylor N, Clay-Williams R, Hogden E, et al. (2015) High performing hospitals: a qualitative systematic review of associated factors and practical strategies for improvement. BMC Health Services Research 15(1): 1-22. BioMed Central.

The National Health Information and Performance Principal Committee (2017) The Australian Health Performance Framework. Available at: http://www.coaghealthcouncil.gov.au/Por tals/0/OOS318_Attachment1.pdf (4 December 2019).

Veillard J, Champagne F, Klazinga N, et al. (2005) A performance assessment framework for hospitals: the WHO regional office for Europe Path project. International Journal for Quality in Health Care 17(6): 487-496.

Veillard J, Cowling K, Bitton A, et al. (2017) Better measurement for performance improvement in low- and middleincome countries: The Primary Health Care Performance Initiative (PHCPI) experience of conceptual framework development and indicator selection. Milbank Quarterly 95(4): 836-883.

Veillard J, Huynh T, Ardal S, et al. (2013) Making health system performance measurement useful to policy makers: aligning strategies, measurement and local health system accountability in Ontario. Healthcare Policy / Politiques de Santé 5(3): 49-65. 